\title{
Laser Performance of Er,Yb:YAl3(BO3)4 Crystals with Different Erbium Concentrations
}

Article · November 2014

DOI: 10.1364/ASSL.2014.AM2A.5

READS

7

6 authors, including:

Konstantin Gorbachenya

Belarusian National Technical University

18 PUBLICATIONS 22 CITATIONS

SEE PROFILE

\section{A.s. Yasukevich}

Belarusian National Technical University

80 PUBLICATIONS 195 CITATIONS

SEE PROFILE
Viktor E Kisel

Belarusian National Technical University

108 PUBLICATIONS 1,223 CITATIONS

SEE PROFILE

Nikolay Leonyuk

Lomonosov Moscow State University

171 PUBLICATIONS 899 CITATIONS

SEE PROFILE 


\title{
Laser Performance of Er, Yb: $\mathrm{YAl}_{3}\left(\mathrm{BO}_{3}\right)_{4}$ Crystals with Different Erbium Concentrations
}

\author{
K.N. Gorbachenya, ${ }^{1}$ V.E. Kisel, ${ }^{1}$ A.S. Yasukevich, ${ }^{1}$ V.V. Maltsev, ${ }^{2}$ N.I. Leonyuk, ${ }^{2}$ and N.V. Kuleshov ${ }^{1}$ \\ 1. Center for Optical Materials and Technologies, Belarusian National Technical University, 65 Nezavisimosti Avenue, \\ Building 17, Minsk, Belarus \\ 2. Geological Faculty, Moscow State University, Moscow 119992/GSP-2, Russia \\ Author e-mail address: gorby@bntu.by
}

\begin{abstract}
The effect of erbium concentration on the laser performance of $\mathrm{Er}, \mathrm{Yb}: \mathrm{YAl}_{3}\left(\mathrm{BO}_{3}\right)_{4}$ crystals was investigated. A maximal output power of $1.6 \mathrm{~W}$ in $\mathrm{CW}$ and $2.7 \mathrm{~W}$ in QCW regimes was obtained at $1522 \mathrm{~nm}$.
\end{abstract}

OCIS codes: (140.3480) Lasers, diode-pumped; (140.3500) Lasers, erbium; (160.5690) Rare-earth-doped materials.

\section{Introduction}

Erbium-doped laser materials are widely used for laser operation in the 1.5-1.6 $\mu \mathrm{m}$ spectral range with promising applications including eye-safe laser range finding, medicine, fiber-optic communication systems, and optical location. Phosphate glasses currently are the leading $\mathrm{Er}^{3+}, \mathrm{Yb}^{3+}$ co-doped laser materials, because they combine very efficient energy transfer from $\mathrm{Yb}^{3+}$ to $\mathrm{Er}^{3+}$ ions $(\eta \approx 90 \%)$ with a long lifetime of erbium upper laser level ${ }^{4} \mathrm{I}_{13 / 2}$ (7-8 ms) and short lifetime of the ${ }^{4} \mathrm{I}_{11 / 2}$ energy level (2-3 $\left.\mu \mathrm{s}\right)$, which prevents the depopulation of this level by means of excited-state absorption and up-conversion processes. However, phosphate glass has poor thermo-mechanical properties (a thermal conductivity of $0.85 \mathrm{~W} \times \mathrm{m}^{-1} \times \mathrm{K}^{-1}$ ), that limits the average output power of Er,Yb:glass lasers due to the thermal effects [1].

The Er,Yb-codoped oxoborate crystals possess abovementioned spectroscopic characteristics and high thermomechanical properties for efficient laser operation. CW room-temperature laser operation was demonstrated for the following Er,Yb-codoped oxoborate crystals: $\mathrm{GdCa}_{4} \mathrm{O}\left(\mathrm{BO}_{3}\right)_{3}$ [2], $\mathrm{LaSc}_{3}\left(\mathrm{BO}_{3}\right)_{4}$ [3], $\mathrm{YCa}_{4} \mathrm{O}\left(\mathrm{BO}_{3}\right)_{3}$ [4]; while for $\mathrm{Li}_{6} \mathrm{Y}\left(\mathrm{BO}_{3}\right)_{3}$ [5], $\mathrm{Sr}_{3} \mathrm{Y}_{2}\left(\mathrm{BO}_{3}\right)_{4}$ [6], $\mathrm{Sr}_{3} \mathrm{Gd}_{2}\left(\mathrm{BO}_{3}\right)_{4}$ [7], and $\mathrm{LuAl}_{3}\left(\mathrm{BO}_{3}\right)_{4}$ [8] quasi-continuous-wave regime of operation was realized. Comparatively recently, excellent laser performance of Er,Yb-codoped $\mathrm{YAl}_{3}\left(\mathrm{BO}_{3}\right)_{4}(\mathrm{YAB})$ and $\mathrm{GdAl}_{3}\left(\mathrm{BO}_{3}\right)_{4}$ crystals was demonstrated [9, 10]. Diode-pumped Er,Yb:YAB laser exhibited a slope efficiency as high as $35 \%$ and output power up to $1 \mathrm{~W}$ at several wavelengths between 1522 and $1602 \mathrm{~nm}$. However, the optimization of erbium concentration and determination of its influence on the laser performance for oxoborate crystals weren't performed.

In this work we present the investigation of the effect of erbium concentration on the laser performance of $\mathrm{Er}, \mathrm{Yb}: \mathrm{YAl}_{3}\left(\mathrm{BO}_{3}\right)_{4}$ crystals.

\section{Spectroscopy}

Er,Yb:YAl ${ }_{3}\left(\mathrm{BO}_{3}\right)_{4}$ single crystals with different erbium concentrations were grown by dipping seeded hightemperature solution growth at a cooling rate $0.2^{\circ} \mathrm{C}-5^{\circ} \mathrm{C}$ per day in the temperature range of $1060^{\circ} \mathrm{C}-1000^{\circ} \mathrm{C}$ using $\mathrm{K}_{2} \mathrm{Mo}_{3} \mathrm{O}_{10}$-based flux. As a result, Er,Yb:YAB crystals with high optical quality and the size up to $20 \times 10 \times 10 \mathrm{~mm}^{3}$ have been obtained The concentrations of the dopants were measured by microprobe analysis to be $0.83 \times 10^{20} \mathrm{~cm}^{-3}$ (1.5at.\%), $1.11 \times 10^{20} \mathrm{~cm}^{-3}$ (2.0at.\%), $1.66 \times 10^{20} \mathrm{~cm}^{-3}$ (3.0at.\%) and $2.22 \times 10^{20} \mathrm{~cm}^{-3}$ (4.0at.\%) for erbium and $6.0 \times 10^{20}$ $\mathrm{cm}^{-3}$ (11at.\%) for ytterbium ions.

The polarized absorption cross-section spectra of Er,Yb:YAB crystal around $980 \mathrm{~nm}$ at room-temperature recorded with a spectrophotometer Cary-5000 are depicted in Fig. 1. A strong absorption band corresponding to transition ${ }^{2} \mathrm{~F}_{7 / 2} \rightarrow{ }^{2} \mathrm{~F}_{5 / 2}$ of $\mathrm{Yb}^{3+}$ ions is centered at $976 \mathrm{~nm}$ with a maximum absorption cross-section of about $2.75 \times 10^{-20} \mathrm{~cm}^{2}$ and bandwidth of $17 \mathrm{~nm}$ (FWHM) in $\sigma$ polarization.

The stimulated emission cross-section spectra calculated by the reciprocity method using the Stark energy level scheme of ${ }^{4} \mathrm{I}_{13 / 2}$ and ${ }^{4} \mathrm{I}_{15 / 2}$ manifolds are plotted in Fig. 2. A number of local maxima are observed in both $\sigma$ and $\pi$ polarizations [9].

\section{Laser experiments}

The laser experiments were performed in Z-shaped cavity. The plane-plane $\operatorname{Er}(\mathrm{Xat} . \%), \mathrm{Yb}(11 \mathrm{at} . \%): \mathrm{YAB}$ (where $\mathrm{X}=1.5$ at.\%; 2at.\%; 3at.\%; 4at.\%) crystal $1.5 \mathrm{~mm}$ long antireflection coated for both pump and lasing wavelengths 
was mounted on the copper thermoelectrically cooled heatsink. The temperature of the active element was kept at $18^{\circ} \mathrm{C}$. As a pump source a $15 \mathrm{~W}$ fiber-coupled (Ø $105 \mu \mathrm{m}, \mathrm{NA}=0.12$ ) laser diode emitting near $976 \mathrm{~nm}$ was used. A combination of two lenses $\left(\mathrm{f}_{1}=\mathrm{f}_{2}=80 \mathrm{~mm}\right)$ was used to focus pump beam into the gain medium. The cavity-mode diameter at the active element was close to the pump beam waist. The transmittance of output coupler was $5 \%$ at the laser wavelength. The setup for laser experiments is presented in Fig. 3.

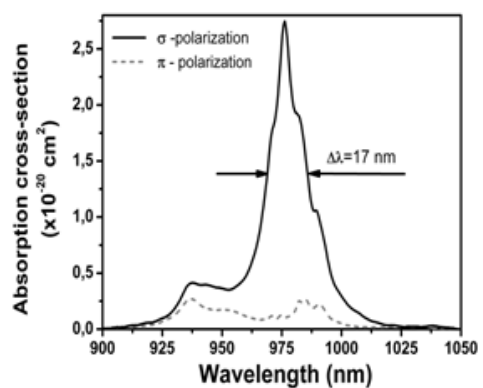

Fig. 1. Room-temperature polarized absorption spectra of Er,Yb:YAB crystal at $1 \mu \mathrm{m}$

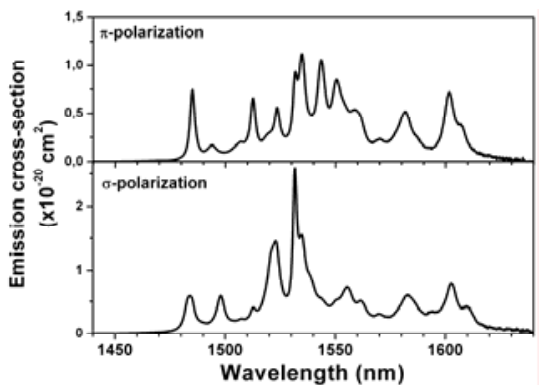

Fig. 2. Emission cross-section spectra of Er,Yb:YAB crystal near $1.5 \mu \mathrm{m}$

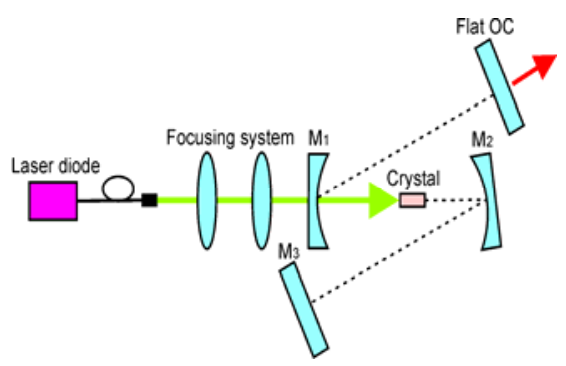

Fig. 3. The setup for laser experiments

Input-output characteristics of CW Er(1.5at.\%),Yb(11at.\%):YAB laser are plotted in Fig. 4. The laser threshold was measured to be about $1.5 \mathrm{~W}$ of absorbed pump power. The maximum $\mathrm{CW}$ output power of $1.2 \mathrm{~W}$ with slope efficiency near $26 \%$ was obtained at $1522 \mathrm{~nm}$ at about $6.2 \mathrm{~W}$ of absorbed pump power. After further increasing of pump power, the rising of output laser power wasn't observed. It provides evidence for the influence of thermal load in the crystal on laser performance. To reduce the thermal load, laser experiments with quasi-CW (QCW) pumping were performed. By using a chopper with a duty cycle of 1:5 in the pumping channel, the maximal output peak power up to $2 \mathrm{~W}$ with slope efficiency of $35 \%$ was obtained at the absorbed peak pump power of $7.3 \mathrm{~W}$ (Fig. 4).

For $\operatorname{Er}(2 \mathrm{at} . \%), \mathrm{Yb}(11 \mathrm{at} . \%): \mathrm{YAB}$ the maximum CW output power of $1.6 \mathrm{~W}$ at $1522 \mathrm{~nm}$ was demonstrated with slope efficiency of $32 \%$ and $1.7 \mathrm{~W}$ laser threshold of absorbed pump power. While for QCW regime of operation laser emission was observed at $1543 \mathrm{~nm}$ with slope efficiency near $32 \%$ at low pump power, however, at an absorbed peak pump power of more than $5.5 \mathrm{~W}$ the emission wavelength switched to $1522 \mathrm{~nm}$ and the slope efficiency was increased drastically to $41 \%$. The maximal output peak power of $2.7 \mathrm{~W}$ was obtained in that case at an absorbed pump peak power of more than $9 \mathrm{~W}$ (Fig. 5).

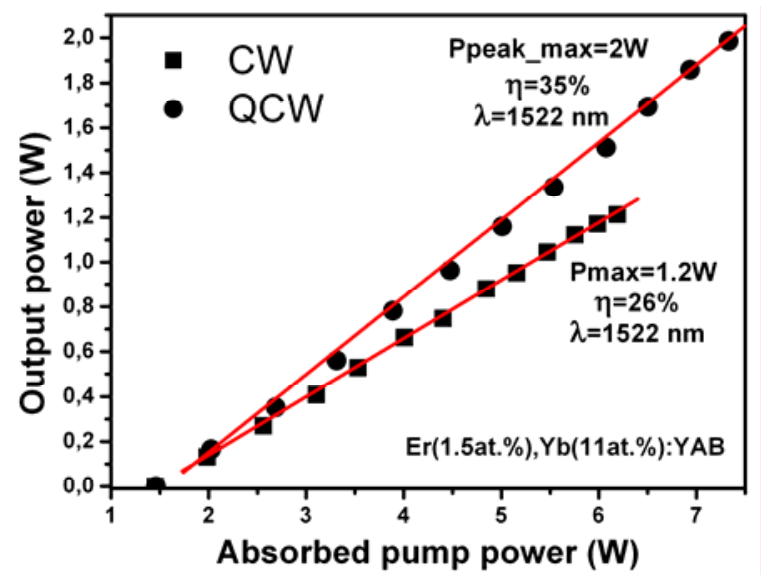

Fig. 4. Input-output characteristics of CW and QCW Er(1.5at.\%),Yb(11at.\%):YAB diode-pumped laser

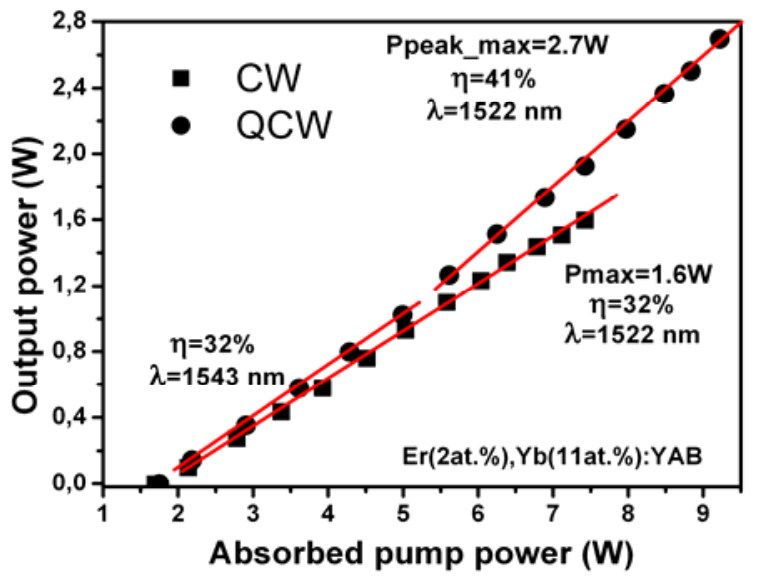

Fig. 5. Input-output characteristics of CW and QCW Er(2at.\%),Yb(11at.\%):YAB diode-pumped laser

Figure 6 shows input-output diagrams of CW and QCW Er(3at.\%),Yb(11at.\%):YAB diode-pumped laser. For CW operation the slope efficiency was reduced to $23 \%$. The maximal output power of $0.6 \mathrm{~W}$ in this case was limited by the damage of active element. To prevent destruction of the crystal further experiments were carried out with quasi-CW pumping. The maximal output peak power of $2.5 \mathrm{~W}$ with slope efficiency of $35 \%$ was obtained at $1522 \mathrm{~nm}$. 
Laser experiments with Er(4at.\%),Yb(11at.\%):YAB were held in QCW regime of operation. The laser threshold was measured to be about $2.6 \mathrm{~W}$ of absorbed peak pump power. The maximum QCW output peak power of $2.2 \mathrm{~W}$ with slope efficiency near $40 \%$ was obtained at $1531 \mathrm{~nm}$ at about $9 \mathrm{~W}$ of absorbed peak pump power (Fig. 7).

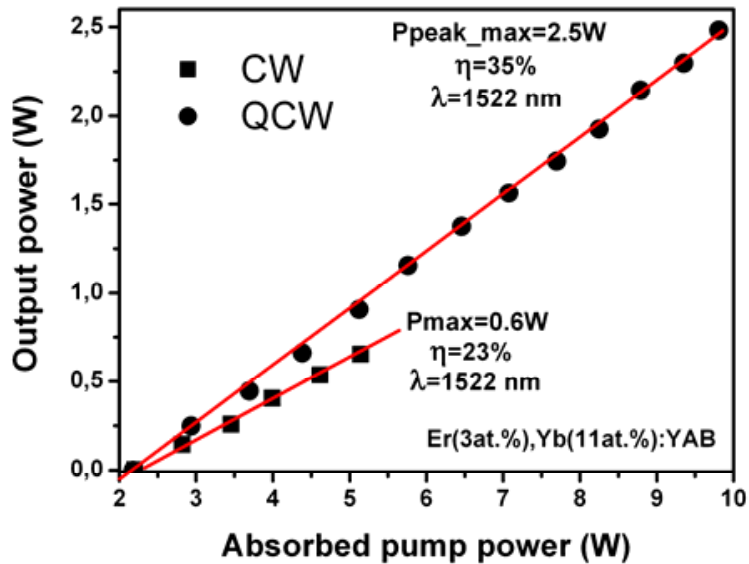

Fig. 6. Input-output characteristics of CW and QCW $\operatorname{Er}(3 a t . \%), Y b(11 a t . \%): Y A B$ diode-pumped laser

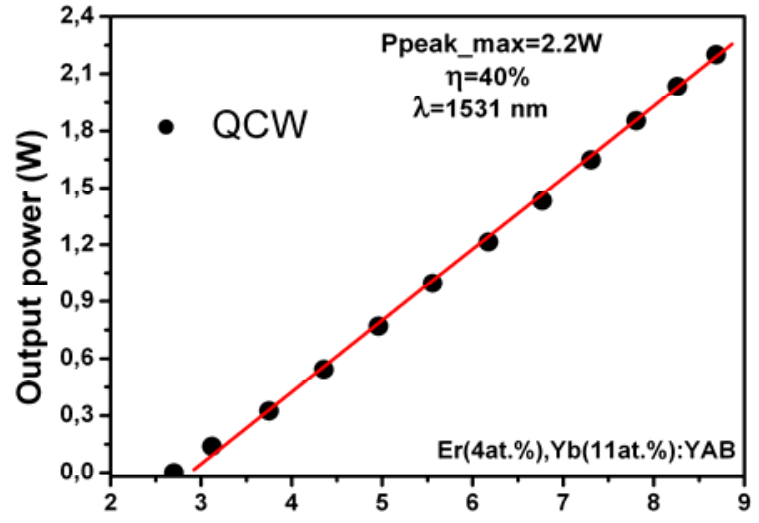

Absorbed pump power (W)

Fig. 7. Input-output characteristics of QCW Er(4at.\%),Yb(11at.\%):YAB diode-pumped laser

The spatial profile of the output beam was close to $\mathrm{TEM}_{00}$ mode with $\mathrm{M}^{2}<1.2$ during all laser experiments. Laser characteristics of Er,Yb:YAl ${ }_{3}\left(\mathrm{BO}_{3}\right)_{4}$ crystals with different erbium concentration are plotted in Table 1.

Table 1. Laser performance of Er, $\mathrm{Yb}: \mathrm{YAl}_{3}\left(\mathrm{BO}_{3}\right)_{4}$ crystals with different erbium concentration

\begin{tabular}{|c|c|c|c|c|}
\hline \multirow{2}{*}{ Crystal } & \multicolumn{2}{|c|}{$\mathbf{C W}$} & \multicolumn{2}{c|}{ QCW } \\
\cline { 2 - 5 } & $\mathbf{\eta}, \mathbf{\%}$ & $\mathbf{P}_{\max }, \mathbf{W}$ & $\boldsymbol{\eta}, \mathbf{\%}$ & $\mathbf{P}_{\text {peak max }}, \mathbf{W}$ \\
\hline $\operatorname{Er}($ 1.5at.\%),Yb(11at.\%):YAB & 26 & 1.2 & 35 & 2 \\
\hline $\operatorname{Er}$ (2at.\%),Yb(11at.\%):YAB & 32 & 1.6 & 41 & 2.7 \\
\hline $\operatorname{Er}(3 a t . \%), Y b(11 a t . \%): Y A B$ & 23 & 0.6 & 35 & 2.5 \\
\hline $\operatorname{Er}(4 a t . \%), Y b(11 a t . \%): Y A B$ & - & - & 40 & 2.2 \\
\hline
\end{tabular}

In conclusion, the effect of high erbium concentration on the laser performance of Er,Yb:YAB crystals was investigated. It was demonstrated, that there is no degradation of QCW laser performance for erbium concentration up to 4.0 at.\%.

\section{References}

1. G. Karlsson, F. Laurell, J.Tellefsen, B. Denker, B. Galagan, V. Osiko, and S. Sverchkov , "Development and characterization of Yb-Er laser glass for high average power laser diode pumping,” Appl. Phys. B. 75, 41-46 (2002).

2. B. Denker, B. Galagan, L. Ivleva, V. Osiko, S. Sverchkov, I. Voronina, J.E. Hellstrom, G. Karlsson, and F. Laurell, "Luminescent and laser properties of $\mathrm{Yb}$,Er-activated $\mathrm{GdCa}_{4} \mathrm{O}\left(\mathrm{BO}_{3}\right)_{3}$ - a new crystal for eyesafe 1.5 micrometer lasers,” Appl. Phys. B. 79, 577-581 (2004).

3. A. Diening, E. Heumann, G. Huber, and O. Kuzmin, "High-power diode-pumped Yb,Er:LSB laser at $1.56 \mu$ m," in Conference on Lasers and Electro-Optics (CLEO), Vol. 6 of 1998 OSA Technical Digest Series, 299-300 (1998).

4. P. Burns, J. Dawes, P. Dekker, J. Pipper, H. Jiang, and J. Wang, “Optimization of Er,Yb:YCOB for cw laser operation,” IEEE J. Quantum Electron. 40, 1575-1582 (2004).

5. Y.W. Zhao, Y.F. Lin, Y.J. Chen, X.H. Gong, Z.D. Luo, and Y.D. Huang, "Spectroscopic properties and diode-pumped 1594nm laser performance of Er, $\mathrm{Yb}: \mathrm{Li}_{6} \mathrm{Y}\left(\mathrm{BO}_{3}\right)_{3}$ crystal,” Appl. Phys. B. 90, 461-464 (2008).

6. J. Huang, Y. Chen, Y. Lin, X. Gong, Z. Luo, and Y. Huang, "High efficient $1.56 \mu \mathrm{m}$ laser operation of Czochralski grown $\mathrm{Er}, \mathrm{Yb}: \mathrm{Sr}_{3} \mathrm{Y}_{2}\left(\mathrm{BO}_{3}\right)_{4}$ crystal," Optics Express 16, 17243-17248 (2008).

7. J.H. Huang, Y.J. Chen, X.H. Gong, Y.F. Lin, Z.D. Luo, and Y.D. Huang, "Growth, polarized spectral properties, and 1.5-1.6 $\mu \mathrm{m}$ laser operation of Er,Yb:Sr $\mathrm{Gd}_{2}\left(\mathrm{BO}_{3}\right)_{4}$ crystal,” Appl. Phys. B. 97, 431-437 (2009).

8. Y. Chen, Y. Lin, J. Huang, X. Gong, Z. Luo, and Y. Huang, "Spectroscopic and laser properties of $\mathrm{Er}^{3+}, \mathrm{Yb}^{3+}: \mathrm{LuAl}_{3}\left(\mathrm{BO}_{3}\right)_{4} \mathrm{Crystal}_{\text {at }} 1.5-1.6$ $\mu \mathrm{m}$," Optics Express 18, 13700-13707 (2010).

9. N.A. Tolstik, S.V. Kurilchik, V.E. Kisel, N.V. Kuleshov, V.V. Maltsev, O.V. Pilipenko, E.V. Koporulina, and N.I. Leonyuk, "Efficient 1 W continuous-wave diode-pumped Er, $\mathrm{Yb}: \mathrm{YAl}_{3}\left(\mathrm{BO}_{3}\right)_{4}$ laser” Opt. Lett. 32, 3233-3235 (2007).

10.K.N. Gorbachenya, V.E. Kisel, A.S. Yasukevich, V.V. Maltsev, N.I. Leonyuk, and N.V. Kuleshov, "High efficient continuous-wave diodepumped Er,Yb:GdAl $3\left(\mathrm{BO}_{3}\right)_{4}$ laser,” Opt. Lett. 38, 2446-2448 (2013). 